\section{PERFORM A 'CROWN DOWN' TECHNIQUE}

Quality Endodontic Distributors Ltd have introduced triniti Nickel Titanium Instruments and SteriFiles. Both are supplied sterile and individually blister packed.

triniti Nickel Titanium Instruments were developed to meet the demands of GDPs who want the benefits of rotary instrumentation at a costeffective price. They have an innovative cross section which allows more free space for debris removal. Whilst retaining its core strength, it also

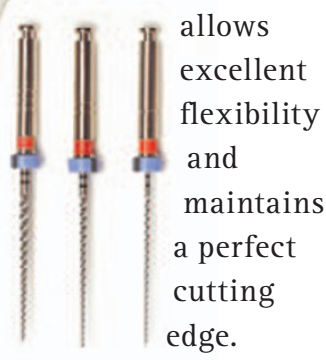

The non-cutting tip reduces the risk of perforations. They enable clinicians to prepare root canals in a simple "crown down' technique requiring fewer instruments.

SteriFiles are designed

for conventional endodontic instrumentation. Supplied in K and $\mathrm{H}$ Type presentations they are manufactured from highgrade stainless steel, which maximises both flexibility and strength. The K Type file features an enhanced non-cutting tip: the first choice for preparing curved and narrow canals.

For further information telephone 01733 404999, email sales@qedendo.co.uk or visit www.qedendo.co.uk.

\section{MAKING PRACTICE COMPLIANCE A DODDLE}

Dentisan offers a range of products to help make HTM 01-05 compliance simple. This includes Bioclear - a biofilm remover for dental unit water lines - as well as Biocleanse Ultra - an all-in-one cleaner and disinfectant, compatible with all the most common surfaces found in dental surgeries.
Dentisan manufactures a comprehensive range of cleaning and hygiene products suitable for multi-surfaces, instrument decontamination, suction systems, impression disinfection, dental unit water lines, hand care, ultrasonic and washer disinfectors, and manual cleaning.

Together with Henry Schein Minerva, Dentisan run a nationwide programme of decontamination and HTM 01-05 seminars, which are suitable for the whole practice team.

For a free sample of Biocleanse Ultra or a free infection control wall-chart, email sample@ dentisan.co.uk. www.dentisan.co.uk

\title{
COMBINING ASPIRATION, SEPARATION AND WASTE ENTRAPMENT
}

Compressed air and gas specialist Absolute Air \&t Gas is launching a new completely self-contained mobile aspirator as an extension to the already substantial range of dental compressors from Ekom, the leading European manufacturer of oilfree air compressors.

A key feature of the new DO M mobile aspirator is that it combines aspiration, separation and waste entrapment into a single built-in separation vessel, making it ideal for dental surgeries where space is limited, where no drainage system is available, or where a de-centralised solution requires point-of-use installation. The new unit also weighs just $36 \mathrm{~kg}$ and achieves exceptional noise levels - less than $48 \mathrm{dbA}$.

Absolute Air \& Gas is offering a standard two year warranty on the Ekom DO M aspirator.

For further information, call 08456056660 or visit www. absoluteairandgas. co.uk.

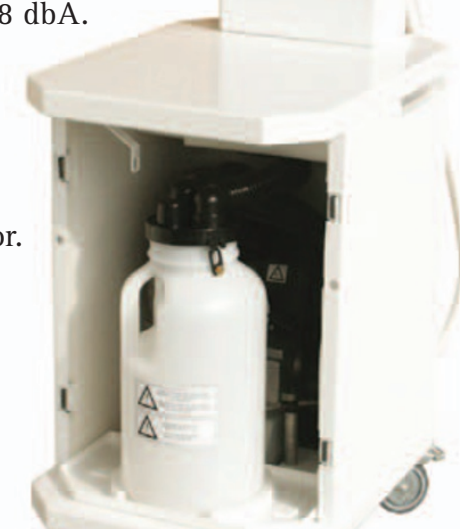

\section{EVERYTHING YOU NEED TO PLACE IMPLANTS}

Dr Nilesh R. Parmar has partnered with Hu-Friedy to release his own dental implant kit.

Available from all major dental dealers, the DR NILESH PARMAR Implant Surgical Kit includes everything needed to expose, retract, place, augment/graft and suture almost all implant sites. It comes with two surgical instrument cassettes, designed to fit almost all autoclaves and washer disinfectors.

Dr Parmar was astonished at the sheer variation in surgical instruments available when he first started placing implants. This led him to form a partnership with $\mathrm{Hu}$-Friedy and their range of instruments. Through close communication and research with instrument specialists, together they devised a surgical set of instruments which Nilesh believes includes all that is needed to successfully place simple to moderate implant cases.

The DR NILESH PARMAR Implant Surgical Kit is available from all major dental dealers. For more information email Atif Ramzan on aramzan@hu-friedy.com or call 07880762079.

\section{NOTA BENE}

Church \&t Dwight UK Ltd, the makers of Arm \&t Hammer toothpaste, ${ }^{1}$ wish to point out that their Enamel Care Sensitive toothpaste with an improved formula that fixes the cause of sensitive teeth and is clinically proven to provide pain relief for up to 16 weeks does so with regular use for 8 weeks. Relief then continues for another 8 weeks.

1. Product news. A 'wow' feeling without sensitivity. Br Dent J 2012: 213: 248. 